\title{
A racionalidade ambiental na construção de tecnologias alternativas para a agricultura familiar: o caso do Serviço de Tecnologia Alternativa - SERTA
}

\section{Environmental Rationality Building Alternative Technologies for Family Farms: The Case of the Service of Alternative Technology - SERTA}

\author{
Sunamita Iris Rodrigues Borges da $\operatorname{COSTA}^{*}$ \\ Marlene Maria da SILVA**
}

\begin{abstract}
RESUMO
A racionalidade instrumental construiu o conceito de tecnologia apropriado pelo sistema capitalista. Esta se tornou fator estratégico para o desenvolvimento econômico e instrumento de controle das externalidades pela artificialização dos processos naturais, gerando graves problemas sociais e ecológicos. Entretanto, pela inacessibilidade econômica e devido aos graves custos socioambientais, fez-se necessária a construção de mecanismos paliativos que favorecessem a transição entre a técnica tradicional e a tecnologia moderna. Nesse contexto, surge o conceito de tecnologias alternativas que, diferenciadas pela ênfase ao baixo custo e à utilização racional de recursos localmente abundantes, define-se pela acessibilidade social e eficiência ecológica. Tal modelo, inspirado na racionalidade ambiental, com ênfase ao suprimento das necessidades das comunidades rurais, tem embasado a atuação de instituições produtoras e difusoras dessas tecnologias voltadas ao desenvolvimento da agricultura familiar no Brasil. Este trabalho apresenta a visão dos agricultores familiares quanto às dificuldades encontradas no processo produtivo e aos resultados obtidos através da atuação de uma dessas instituições, o Serviço de Tecnologias Alternativas, especificamente, a partir da análise de suas atividades no semiárido pernambucano, na unidade localizada em Ibimirim-PE.
\end{abstract}

Palavras-chave: racionalidade ambiental; tecnologia alternativa; SERTA - Serviço de Tecnologia Alternativa.

\footnotetext{
"* Mestra em Desenvolvimento e Meio Ambiente, com ênfase em Gestão e Políticas Ambientais (PRODEMA -UFPE). Integra o Grupo de Pesquisa em Inovação Tecnologia e Território (GRITT-UFPE). E-mail: sunamitairis@gmail.com

"* Doutora em Geografia (Geografia Humana) (USP). Professora adjunta do Departamento de Ciências Geográficas da Universidade Federal de Pernambuco (UFPE).

E-mail:mms@truenet.com.br
} 


\begin{abstract}
Instrumental rationality built the concept of technology appropriated by the capitalist system. This has become a strategic factor for economic development and instrument of externalities control by artificial state of natural processes, creating serious social and ecological problems. However, through economic inaccessibility and due to severe environmental costs, it was necessary to build palliative mechanisms that promote the transition from the traditional technique to modern technology. In this context, the concept of alternative technologies arises and, differentiated by the emphasis on low cost and efficient use of locally abundant resources, is defined by social accessibility and ecological efficiency. This model, inspired by the environmental rationality with emphasis on supplying the needs of rural communities, has been the foundation of the actions of institutions that produce and diffuse these technologies focused on the development of family farming in Brazil. This paper presents the vision of family farmers about the difficulties encountered in the production process and the results obtained through the agency of one of these institutions, the Service of Alternative Technologies (SERTA), specifically, from the analysis of their activities in semi-arid region of Pernambuco (Brazil), in the unit located in Ibimirim-PE.
\end{abstract}

Keywords: environmental rationality; alternative technology; Service of Alternative Technology.

\section{Introdução}

De acordo com Vargas (1994), a concepção contemporânea de tecnologia enquanto atividade de transformação do mundo e resolução de problemas práticos, baseada em conhecimentos científicos e regida por processos cientificamente controlados, surge no período renascentista. Seu papel assume desde então significativa relevância histórica ao ponto de Ellul (1954) conceber que não foi o Capitalismo que criou o mundo contemporâneo, mas a máquina.

Esse emblema renascentista da capacidade humana de controlar os fenômenos naturais possibilitou a formação de componentes característicos do sistema capitalista: a produção e o consumo em massa. De igual modo, a visão mecanicista da realidade estabeleceu na sociedade moderna valores de eficiência, funcionalidade e produtividade que fizeram do progresso tecnológico não um instrumento a serviço da humanidade, mas um elemento usado para a superexploração do trabalho de muitos em benefício de poucos humanos.

Nesse artigo, as autoras apresentam uma análise de duas das principais compreensões do papel da tecnologia dentro do sistema capitalista, evidenciando as crises social e ambiental geradas pelo destaque que a racionalidade instrumental conferiu aos valores econômicos.

Em seguida, faz-se referência à compreensão alternativa do uso e função da tecnologia, pautada na racionalidade ambiental (LEFF, 2002) e na compreensão do complexo ordenamento da natureza que torna a sua artificialização um caminho economicamente pouco viável, uma vez que tem como destino a degradação de recursos e o comprometimento do futuro do planeta.

Uma vez que essas ideias têm embasado a atuação de diversas organizações brasileiras que buscam, pelo uso de tecnologias apropriadas às necessidades sociais das comunidades rurais, desenvolver a agricultura familiar no Brasil, por fim, apresentar-se-á a avaliação de agricultores sobre dificuldades encontradas, os principais objetivos e a relevância dos resultados obtidos pela aplicação do modelo tecnológico alternativo.

Para fins de identificação dos resultados das tecnologias alternativas produzidas e difundidas por organizações de apoio ao desenvolvimento rural sustentável, segundo a visão dos agricultores familiares que as aplicaram em sua unidade produtiva, selecionou-se 120 agricultores, de 11 municípios do Agreste e Sertão pernambucanos, formados pelo Serviço de Tecnologia Alternativa (SERTA), em sua agência localizada em Ibimirim-PE.

Nesse sentido, o presente trabalho contribui para a reflexão dos padrões que regem a produção de bens e serviços em um contexto de reprodução ampliada do capital, alienando-se as graves e potencialmente irreversíveis consequências. Igualmente, destaca a necessidade de estabelecer, no contexto produtivo, primeiro e principalmente, valores sociais e ambientais, os quais se mostram economicamente viáveis.

Objetiva-se, com tais reflexões, identificar em que medida, na avaliação dos agricultores familiares, o uso de tecnologias alternativas lhes proporcionou resultados produtivos, ainda mais se considerando o contexto no qual estão 
inseridos os pesquisados, a saber, o semiárido do Estado, a rigor estigmatizado como um ambiente de improdutividade.

As reflexões ora apresentadas são resultado da pesquisa que originou a dissertação de mestrado Impactos das tecnologias alternativas no desenvolvimento ambientalmente racional da agricultura familiar no semiárido pernambucano, apresentada ao Programa de Pós-Graduação em Desenvolvimento e Meio Ambiente da Universidade Federal de Pernambuco (PRODEMA-UFPE).

\section{A racionalidade (instrumental/econômica) da tecnologia no mundo capitalista}

A construção da racionalidade instrumental perpassa pela história oficial do pensamento, remontando à passagem da mitologia para a filosofia e à dessacralização da natureza pelo catolicismo vencedor, mas, principalmente, remete ao renascimento, período no qual o conceito moderno de ciência foi consolidado.

De acordo com Vargas (1994), é igualmente durante o período renascentista que surge a definição de tecnologia tal como nos deparamos atualmente: a atividade de transformação do mundo, resolução de problemas práticos, baseada em conhecimentos científicos e criada através de processos cientificamente controlados. Contudo, tal expressão é igualmente empregada para referir-se aos resultados desses estudos, que podem provocar alterações na estrutura técnica socialmente construída. Por sua vez, tem a capacidade de promover transformações na própria sociedade, podendo, além de modificar processos produtivos, transformar hábitos e valores culturais.

Ainda que a ideologia renascentista tenha se fundamentado no ideal de retorno à natureza, serviu antes aos propósitos de dominação colonial e contribuiu para a formação de um modelo mecanicista de pensamento. Segundo Sábato (1993),

O Renascimento se produziu por intermédio de três paradoxos:

1. Foi um movimento individualista que terminou na massificação.

2. Foi um movimento naturalista que terminou na máquina.

3. Foi um movimento humanista que terminou na desumanização. (SÁBATO, 1993, p. 19-20).
Nesse contexto, a natureza configurou-se como espaço a ser dominado pela razão, passível de ser explicada por "leis gerais", cientificamente elaboradas e, como tal, explorada a fim de fazer prosperar o capitalismo, em expansão. A essa racionalidade chamou-se instrumental.

Sob essa ótica, analisando-se as contribuições que tratam das funções da tecnologia no mundo atual, se destacam duas visões. A primeira entende a tecnologia como fator estratégico para o "desenvolvimento econômico", compreendido como o aumento da produção e acúmulo de riqueza.

De acordo com esse conceito, o desenvolvimento estaria centrado, principalmente, na produção industrial, por meio da captação das demandas existentes, da ampliação da capacidade produtiva, da criação de produtos e processos capazes de abrir novos mercados e da ampliação da porção orgânica do capital, diminuindo os custos e fornecendo vantagens competitivas e comparativas ante a concorrência.

A raiz dessas concepções pode ser identificada na própria consolidação do Capitalismo Industrial, desencadeado pelo modelo de produção fordista. Segundo Harvey (2002), o Fordismo foi concretizado no pós-Segunda Guerra Mundial, com o apoio do Estado keynesiano. Nesse momento, as grandes corporações industriais dispunham de tecnologia amadurecida, capacidade de ampliação da demanda e ampla estrutura produtiva fundamentada em grandes investimentos de capital fixo.

Entretanto, a estabilidade e a expansão do Fordismo, conquistadas a preço elevado após a depressão de 1929 , apenas antecediam um novo período de crise. Já na década de 1960, surgem graves problemas diante do início da industrialização em países subdesenvolvidos e o consequente aumento da competição internacional.

Essa conjuntura, associada à instabilidade financeira, lançou o alerta para uma nova grande depressão, ao deixar significativa parte da estrutura produtiva fordista ociosa. De acordo com Harvey (2002), isso serviu para impulsionar uma tentativa de racionalizar e reestruturar a produção e intensificar o controle sobre a força de trabalho. Para tanto, se utilizaram elevadas taxas de inovação tecnológica, comercial e organizacional, por meio da automação, novas linhas de produção, construção de novos nichos de mercado, dispersão geográfica, fusões de empresas e medidas para acelerar o tempo de giro do capital. Esse conjunto de características recebeu o nome de Modelo de Produção Flexível.

Nessa conjuntura, a capacidade técnica acumulada e a evolução da competência tecnológica tornaram-se imperati- 
vas para o "desenvolvimento" econômico, destacando-se o papel das inovações voltadas para a ampliação da indústria e a consolidação de sua capacidade competitiva.

A nova ordem instaurada baseia-se em uma concepção da técnica como fator facilitador da superexploração do trabalho e da tecnologia como elemento de diminuição dos custos da produção ao substituir a necessidade de mão de obra pela mecanização do processo produtivo.

Diante da ampliação exponencial da capacidade produtiva, chegamos a três impasses: primeiro, ao mesmo tempo em que a necessidade de mão de obra se reduz, somando-se a uma fragilização da força de trabalho empregada, a demanda por produtos deveria se elastecer na mesma proporção que a possibilidade de oferta, o que não pode ocorrer; segundo, o processo produtivo utiliza recursos que são extraídos da natureza, os quais não se ampliam na mesma proporção em que são consumidos, como nos aponta Altvater (1995) ao demonstrar o balanço energético do planeta; e, finalmente, a produção gera resíduos que são depositados no sistema (Terra), destruindo o meio onde vivem as espécies humana e não humanas e os recursos necessários à satisfação das necessidades biológicas, potencialmente ampliáveis.

Tais fatores implicam em um limite claro ao desenvolvimento nos padrões tradicionalmente concebidos. Essa constatação vai de encontro à compreensão de progresso ilimitado e da Terra como fonte inesgotável de recursos autorrenováveis, que corrobora o segundo conceito do papel da tecnologia como instrumento de controle das externalidades $^{1}$ geradas no processo produtivo. Os problemas causados por uma máquina, processo ou substância, nesse conceito, seriam submetidos à racionalidade humana e solucionados com a criação de outra máquina, processo ou substância, em um ciclo baseado na infinitude dos recursos naturais.

Essa supervalorização da capacidade humana de dominar a natureza e seus processos instituiu uma crítica ambiental à sociedade industrial, centrada nos crescentes custos da reprodução do sistema produtivo nos moldes traçados pelos apologistas do "desenvolvimento". Esses crescentes custos referem-se à segunda lei da termodinâmica, a lei da entropia, segundo a qual parte da energia transformada em trabalho se degrada e não pode ser recuperada.
Boulding apud Mota (2010, p. 301) a define da seguinte maneira:

A entropia é representada pela quantidade de energia que não é mais capaz de realizar trabalho e também é a medida do grau de desordem na natureza. Nos processos naturais a energia livre é transformada em energia latente, dissipada no meio ambiente, portanto não mais disponível para gerar vida nova.

Uhlmann (2002, p. 35) afirma que, "à medida que a entropia aumenta, há um decréscimo em energia disponível. A cada vez que um evento ocorre no mundo, alguma quantidade de energia fica indisponível para trabalho futuro. Esta energia não disponível [...] é a poluição", a qual, tanto para Uhlmann (2002, p. 51. Grifo nosso) quanto para Mota (2010, p. 6), atua na degradação dos recursos naturais, voltando-se contra os próprios elementos do sistema e quebrando o frágil equilíbrio que rege o planeta. $\mathrm{O}$ uso intensivo dos recursos naturais, portanto, é altamente degradante e os danos gerados são potencialmente irreversíveis.

Sobre os efeitos nocivos dos objetivos da tecnologia, baseados nos dois referenciais citados, igualmente, podem-se citar exemplos dentro do setor primário. No caso brasileiro, o setor somou o uso da tecnologia como ferramenta facilitadora da ampliação da exploração da força de trabalho à histórica concentração fundiária e à produção destinada, primordialmente, ao mercado externo, que se caracteriza por apresentar custos sociais, econômicos e ecológicos significativos.

Entretanto, ainda que entre a técnica tradicional e a moderna tecnologia em padrões economicistas existam marcantes diferenças ideológicas, não se pode conferir apenas aos elementos high tech a capacidade de gerar danos ambientais. Isso está expresso na contribuição de Santos (1999). Para ele, enquanto certos modelos, baseados no uso intensivo de capital e tecnologia, são, por opção, poluidores, aqueles que estão, pela falta destes elementos, presos ao uso de técnicas tradicionais ineficientes, o são por falta de opção.

Como exemplificação disso tem-se a compleição da estrutura de degradação presente no setor agropecuário brasileiro. De um lado, aparece a grande propriedade, onde

\footnotetext{
${ }^{1}$ De acordo com Callan e Thomas (2009), externalidades, para economia, consistem em gerar benefícios ou custos para indivíduos não envolvidos no processo do mercado. São, portanto, uma falha de mercado, nas quais se enquadram os riscos e danos ambientais.
} 
duas situações são facilmente identificadas: a) a adoção de estruturas de produção tecnicamente avançadas, mas cujos objetivos do emprego científico-tecnológico giram em torno da conquista de espaço no mercado mundial; b) os latifúndios localizados em regiões onde os reduzidos custos de mão de obra possibilitam baixos investimentos em maquinário e a cultura tradicionalista de produção os torna praticantes da degradação. Nos dois casos, as decisões levam em conta a mais vantajosa relação econômica de custo e benefício, em curto prazo, e os danos ecológicos e sociais são opção implícita ao modelo adotado.

No outro sentido, tem-se a agricultura familiar, estrutura produtiva que se destacou pela capacidade de absorver mão de obra, mas que, em sua maioria, se compõe de produtores economicamente frágeis e impossibilitados, pelos padrões de investimentos no setor e pelas dificuldades de inserir-se em mercados dinâmicos, de aderir aos padrões da tecnologia moderna, tidos como ideais. Para esses, as reduzidas condições de renda e educação e a falta de acesso aos meios de produção, entre os quais se encontra a terra, tornou-os praticantes e usuários de técnicas tradicionais, em muitos casos causadoras de danos ambientais.

Um exemplo dessas práticas agrícolas predatórias é a queimada controlada. De acordo com o Portal São Francisco (PSF, 2010), embora as queimadas sejam associadas ao desmatamento e se tenha conhecimento da sua interferência direta na qualidade do ar, nos solos, na vegetação atingida pelo fogo e nos recursos hídricos, mais de $98 \%$ das queimadas praticadas no Brasil são de natureza agrícola.

A discussão sobre os danos sociais e ecológicos causados pela supervalorização tecnológica por parte da racionalidade instrumental e sobre as dificuldades geradas por certas técnicas tradicionais, deslocadas de seu contexto histórico e espacial e transformadas pela lógica produtivista instrumental, demonstra a insuficiência e o prejuízo que qualquer um dos extremos é capaz de promover. Logo, evidencia-se a necessidade de mudança do paradigma vigente que fundamenta o papel da tecnologia.

Nesse sentido, o objetivo central passa a ser construir uma visão de desenvolvimento que abranja, primeiro e principalmente, a dimensão social e tenha como preocupação as urgências ambientais. Para tanto, torna-se imperativa a introdução de valores ecológicos na produção de bens e serviços, independente do setor econômico. Tal compreensão alternativa do mundo é apresentada por Leff (2002) por meio do conceito de racionalidade ambiental.

\section{A racionalidade ambiental como forma alternativa de compreensão do mundo}

A fim de resgatar a compreensão integrada dos fenômenos e seu meio, Leff (2002) construiu a ideia de racionalidade ambiental como crítica à visão instrumental do mundo, visão esta que, embora tenha contribuído para significativos avanços em áreas socialmente importantes, foi apropriada pelo capitalismo, construindo o ambiente de crise vivenciado atualmente.

$\mathrm{O}$ autor assume, como precondição para a racionalidade ambiental, desenvolver uma compreensão do ambiente que ultrapasse a simples dimensão de meio físico. Para Leff (2002), o ambiente aparece como categoria sociológica, integrada por processos de ordem física e social, os quais foram dominados e excluídos pela racionalidade econômica.

Essa construção teórica apresenta como fundamento central a complexidade ambiental entendida por Leff (2002; 2008) e Morin (2005) como determinante para a compreensão do ambiente em sua totalidade. Consideram que a separação entre o fenômeno observado e o meio onde este se processa comprometeu seu entendimento.

Aplicada a ideia de complexidade, a racionalidade ambiental está pautada em um conceito próprio de saber, o saber ambiental. Leff (2008) o define como o saber que abrange tanto o campo externalizado pela racionalidade econômica, científica e tecnológica da modernidade quanto os saberes marginalizados e subjugados pela centralidade do logos científico.

A racionalidade instrumental foi apropriada de modo a operacionalizar a natureza a serviço da acumulação de riqueza. A racionalidade ambiental, por sua vez, é guiada por princípios de sustentabilidade e complexidade. Tem como objetivo central "satisfazer as necessidades sociais das comunidades rurais, respeitando seus valores culturais e desenvolvendo o potencial produtivo dos ecossistemas e de seus saberes práticos" (LEFF, 2002. p. 87).

Considerando que satisfazer essas necessidades pressupõe a criação de condições produtivas que privilegiem a autonomia, a questão tecnológica ganha destaque. Todavia, uma visão alternativa da tecnologia necessita instaurar-se, em oposição aos principais conceitos de suas funções no mundo capitalista, a fim de desenvolver os valores ecológicos e as condições técnicas fundamentais para a (re) afirmação das formas de relação produtiva das comunidades rurais com a natureza. 


\subsection{A emergência de um novo paradigma: a tecnologia alternativa}

A consciência dos danos causados pela racionalidade que impulsionou a busca pelo desenvolvimento, por meio da dominação da natureza através da tecnologia, conduziu a comunidade científica à compreensão do imperativo de transformação dos padrões que regem a sociedade capitalista. Dessa forma, espera-se construir modelos que visem melhor aproveitar os esgotáveis recursos de que o planeta dispõe, em um contexto de necessidades potencialmente ampliáveis e em benefício destas e de futuras gerações.

Embora seja a ciência moderna um dos responsáveis pela visão mecanicista e compartimentada da natureza, a busca por soluções apropriadas para a realidade atual passa pela utilização do conhecimento científico. Mas supõe, igualmente, o resgate dos saberes tradicionais característicos de cada grupo social, integrando as diferentes formas de compreender o mundo em uma visão complexa do ambiente.

Essa articulação, pautada na racionalidade ambiental, na visão integrada e integradora dos conhecimentos e no diálogo relacional entre os homens e a natureza, visa identificar novas formas, funções e compreensões da tecnologia. Procura também articular o desenvolvimento social e econômico à preservação e à conservação do ambiente.

Nesse contexto, a visão alternativa concebe a tecnologia não como ferramenta para aumento da produção e diminuição de custos, mas como meio para melhorar a alocação dos finitos recursos disponíveis. Compreende-a não como mecanismo destinado a elaborar soluções técnicas para resolver os impactos ambientais gerados, mas como forma de desenvolver processos que os reduzam significativamente, ao mesmo tempo em que promovam a inclusão social e a conquista da elevação real da qualidade de vida das populações fragilizadas pela dinâmica do capitalismo.

\subsubsection{Origem da discussão e definição de tecnologia alternativa}

O conceito de tecnologia alternativa surgiu como uma crítica à visão de eficiência baseada em critérios econômicos como determinantes para a escolha tecnológica mais apropriada.

Segundo princípios da economia neoclássica, as escolhas das tecnologias a serem utilizadas são definidas pelas leis de livre mercado. As empresas decidem, a fim de melhor resistirem à concorrência, que tecnologia atende, de forma mais "eficiente", às suas necessidades produtivas. $\mathrm{O}$ mercado, por sua vez, escolhe os produtos segundo o preço que está disposto a pagar pelos mesmos, diante da informação de que dispõe para a tomada de decisão.

Os efeitos sociais e ambientais dessas escolhas, sejam positivos ou negativos, são vistos como externalidade, uma falha de mercado por sub ou superestimar os benefícios da transação entre produtor e consumidor, gerando uma ineficiência alocativa de recursos. Esses efeitos, segundo Callan e Thomas (2009), seriam resolvidos também pela atuação livre do mercado, através da oscilação da disposição dos consumidores a pagar por produtos que utilizem tecnologias menos agressivas, indicando o valor conferido pelo mercado à qualidade ambiental.

Contudo, tais soluções de mercado subentendem que a informação de que dispõe o consumidor é perfeita, garantindo-lhe todas as ferramentas necessárias a sua melhor escolha, o que não acontece fora dos modelos econômicos.

De acordo com Castor (1983), essa concepção conferiu uma suposta inocência ideológica à seleção de modelos tecnológicos, admitindo-se a autônoma escolha por parte dos atores envolvidos. Tais ideias mostram-se incoerentes se considerarmos que a tecnologia não só é responsável por modificar sistemas de produção, como também cria valores capazes de alterar estruturas sociais.

Essa compreensão passa a ser ressaltada na década de 1970, quando Schumacher (1973) apresenta uma crítica ao modelo neoclássico e propõe uma análise alternativa da tecnologia, lançando as ideias do envolvimento da sociedade na escolha adequada das tecnologias e de critérios de eficiência social e ambiental como parâmetro central de análise.

A aplicação desse conceito, todavia, foi inicialmente proposta como solução paliativa. De acordo com Guanziroli et al. (2001), as tecnologias alternativas foram assim denominadas porque surgiram como alternativa para a capitalização dos agricultores familiares a fim de, posteriormente, inseri-los na trindade da revolução verde (variedades selecionadas, agroquímicos e irrigação). Para Guanziroli et al. (2001, p. 23),

As alternativas pesquisadas representavam, em grande medida uma inversão da lógica do pacote tecnológico da revolução verde: em vez de adaptar, por intermédio de investimentos elevados (agroquímicos e irrigação), os ecossistemas agrícolas às variedades de alta capacidade 
produtiva (HYV - High Yield Varieties), passou-se a pesquisar alternativas de adaptação das variedades às restrições de cada ecossistema agrícola [...] [considerando como apropriados] determinados tipos de máquinas e equipamentos, de menor porte, projetados para operar com eficiência em áreas mais exíguas [...].

Contudo, anunciados os problemas ambientais gerados pela manipulação e extrema artificialização do meio natural, as tecnologias alternativas começaram a figurar como solução plausível para todos os agricultores, familiares ou patronais.

Porém esta anunciada viabilidade não está intimamente ligada à forma, mas ao conceito de tecnologias alternativas, comportando uma noção ambientalmente racional de eficiência em uma adequação que não pode desprezar o contexto cultural, social e econômico em que a tecnologia é aplicada. Do contrário, surgiriam dificuldades, por exemplo, de sua adequação "ótima" às condições de produção, tais como a inacessibilidade aos recursos necessários à aquisição das tecnologias por parte da população, resistência cultural às transformações tecnológicas e degradação ambiental.

Nesse sentido, a seleção de tecnologias apropriadas a cada contexto produtivo deve levar em consideração os condicionantes para a produção. Como exemplo, Guanziroli et al. (2001) citam as diferenças das características de cada tecnologia aplicada nos centros mundiais do desenvolvimento: no caso dos EUA, devido ao elevado custo da oportunidade do trabalho, as tecnologias concentravam-se em poupar a utilização desse fator. Já na Europa, a restrita disponibilidade de terras para o desenvolvimento da agricultura concentrou o uso de tecnologia para o aumento da produtividade.

Essa concepção corrobora a ideia de que a tecnologia desenvolvida, bem como o conhecimento que possibilita sua construção, estão imersos em um contexto sociocultural definido, do qual depende sua aplicação eficiente, como nos alude Altvater $(1995$, p. 26), que considera a estrutura técnica e as construções tecnológicas um produto social e cultural. As Ciências, Tecnologias e Inovações (CT\&Is) são compreendidas como uma expressão de um contexto específico de qualificações e competências culturais, hábitos e saberes sociais, fundamentais na sua construção e aplicação, as quais tipificam determinados espaços e são elaboradas em períodos (tempos) variáveis.

Tais ideias têm fomentado, no Brasil, a atuação de organizações que, diante da histórica depreciação do trabalho e trabalhador rurais, da marginalização da agricultura familiar e da insuficiência das políticas públicas para esse segmento, adotam princípios da racionalidade ambiental, produzindo, adaptando e difundindo tecnologias alternativas destinadas à produção familiar sustentável.

A tecnologia alternativa é denominada de tecnologia intermediária, adequada, correta, comunitária, participativa, ecotecnologia ou, mais frequentemente, tecnologia apropriada (JÉQUIER, 1976; ABIKO, 2003). Em todos esses casos, seu conceito encontra-se imbuído das mesmas preocupações com sustentabilidade e complexidade que norteiam a ideia de racionalidade ambiental (LEFF, 2002).

Considera-se tecnologia alternativa aquela que enfatiza o uso de fatores de produção (recursos naturais, capital e trabalho) que são abundantes localmente e minimiza o uso dos que são localmente escassos, amortizando a necessidade de importar tecnologia e apresentando soluções para as dificuldades de obtenção de recursos por meio da busca pela interação harmoniosa do homem com o ambiente.

De acordo com Abiko (2003), as tecnologias alternativas ocupam um espaço entre a técnica tradicional e a tecnologia moderna. Isso não as caracteriza como inferiores, uma vez que surgem da visão integrada das necessidades sociais e ambientais, podendo fazer uso de elementos dessas duas modalidades na construção de uma solução adequada.

A técnica tradicional configura-se por sofrer poucas alterações desde sua origem, devido à ausência de uma base teórica para os conhecimentos que a configuram. Contudo, atende consideravelmente as necessidades sociais por ser construída a partir do conhecimento prático do ambiente e de como viver nele.

A tecnologia moderna, por sua vez, altera-se rapidamente na medida em que se transformam e evoluem os conhecimentos técnicos e científicos em que se baseia. Sendo parte integrante de um sistema organizacional exógeno às comunidades locais, ela se apropria dos recursos e utiliza-se da mecanização com vistas ao aumento da produtividade e "eficiência", baseada em intenso investimento de capital. Torna-se, portanto, dependente do consumo ampliado.

A tecnologia alternativa caracteriza-se pela utilização dos recursos existentes nas comunidades locais (capital, mão de obra e materiais), efetivando-se pela participação das comunidades em sua construção. Essa propriedade lhe acrescenta um forte componente cultural e uma melhor adequação às especificidades ambientais e produtivas.

No Quadro 1 encontra-se a sistematização das características da técnica tradicional e das tecnologias moderna e alternativa quanto aos fatores que as definem: 
QUADRO 1 - CARACTERÍSTICAS DA TÉCNICA TRADICIONAL E DAS TECNOLOGIAS ALTERNATIVA E MODERNA

\begin{tabular}{|c|c|c|c|}
\hline Materiais & $\begin{array}{l}\text { - Simples; } \\
\text { - Matérias-primas locais; } \\
\text { - Retirados ou produzidos no local; } \\
\text { - Utilização de poucos componentes. }\end{array}$ & $\begin{array}{l}\text { - Sofisticados; } \\
\text { - Matérias-primas de diversos locais; } \\
\text { - Produzidos fora do local de uso; } \\
\text { - Frequentemente há pré-fabricação } \\
\text { de componentes. }\end{array}$ & $\begin{array}{l}\text { - Simples ou sofisticados; } \\
\text { - Matérias-primas locais; } \\
\text { - Produzido de forma racionalizada } \\
\text { no canteiro; } \\
\text { - Pré-fabricados que não necessitam } \\
\text { de equipamento pesado. }\end{array}$ \\
\hline Mão de obra & $\begin{array}{l}\text { - Intensiva; } \\
\text { - Usuário ou pequenos construtores. }\end{array}$ & $\begin{array}{l}\text { - Parcialmente substituída por } \\
\text { equipamentos; } \\
\text { - Empregada e terceirizada. }\end{array}$ & $\begin{array}{l}\text { - Intensiva; } \\
\text { - Usuário ou pequenos construtores. }\end{array}$ \\
\hline Organização & - Simples. & $\begin{array}{l}\text { - Complexa, só parcialmente no } \\
\text { local da produção. }\end{array}$ & $\begin{array}{l}\text { - Complexa, na maioria no local da } \\
\text { produção. }\end{array}$ \\
\hline Transportes & - Homem e animais. & - Máquinas especializadas. & - Máquinas leves. \\
\hline $\begin{array}{c}\text { Formas de } \\
\text { Conhecimento } \\
\end{array}$ & - Saberes populares. & - Conhecimento científico. & $\begin{array}{l}\text { - SaberesPopulares }+ \text { Conhecimento } \\
\text { Científico. }\end{array}$ \\
\hline $\begin{array}{c}\text { Princípios } \\
\text { Teóricos }\end{array}$ & - Experimentação empírica. & - Racionalidade Instrumental. & - Racionalidade Ambiental. \\
\hline
\end{tabular}

FONTE: ABIKO, 2003 (adaptado pelas autoras).

De acordo com autores como Schumacher (1973; 1975), Dickson (1975), Lovins (1976), CODETEC (1979), Winner (1979), Castor (1983) e Abiko (2003), para que determinada tecnologia seja considerada alternativa ou apropriada, deve atender simultaneamente a um conjunto de critérios:

1. Privilegiar a integração com o ecossistema onde é aplicada, exercendo reduzido impacto ambiental e favorecendo a relação harmoniosa entre homem e ambiente;

2. Empreender baixo uso de capital, tornando-se acessível às camadas da população com menor renda e restrito acesso a crédito;

3. Favorecer a utilização dos recursos mais abundantes localmente, incluindo a absorção da mão de obra, com vistas à autonomia local;

4. A tecnologia necessita ser de fácil compreensão e adaptação às necessidades sociais, a fim de facilitar sua absorção;

5. Não exigir elevados e específicos níveis de especialização, possibilitando o treinamento e a capacitação da mão de obra pouco qualificada e reduzindo as barreiras culturais à sua utilização;

6, Ser de domínio público.

Ao realizar o levantamento de uma amostragem de 32 dessas organizações, Costa (2011) identificou três categorias, de acordo com seu caráter político e institucional e sua dedicação, parcial ou exclusiva, à reestruturação socioambiental do empreendimento agrícola familiar, no que a inserção de um padrão alternativo de tecnologia é determinante. As categorias identificadas são:

a) Organizações Públicas de Pesquisa Agropecuária, dedicadas à produção de pesquisa e desenvolvimento $(\mathrm{P} \& \mathrm{D})$ para o setor agropecuário nacional e estadual, apresentam alguns projetos voltados para a inserção de novas tecnologias na agricultura familiar. Entretanto, por verem no agronegócio o caminho mais seguro para o crescimento econômico do país, têm sua atenção voltada para a grande empresa agrícola;

b) Redes de Intercâmbio e Difusão de Tecnologias Alternativas que, embora não estejam focadas 
na produção de novas tecnologias, identificam na colaboração entre os atores, indivíduos ou instituições, seja por meio da troca de experiências vivenciadas localmente, seja pelo intercâmbio ou pela interação para a produção de tecnologias alternativas, um importante instrumento de discussão e cooperação na solução de problemas comuns aos envolvidos no processo;

c) Institutos Produtores e Difusores de Tecnologias Alternativas voltados à pesquisa e à difusão das tecnologias produzidas, adaptadas ou importadas através das redes de intercâmbio ou de cooperações isoladas com outras instituições. Essas organizações caracterizam-se por uma ligação com a comunidade onde atuam e por dedicarem-se, igualmente, à (re)educação dos agricultores e jovens com o objetivo de fornecer-lhes as ferramentas necessárias para melhoria de sua condição social, por meio da transformação de sua relação com a natureza dentro do processo produtivo.

\section{O caso do Serviço de Tecnologias Alternativas: SERTA}

Dentre as várias instituições identificadas no levantamento das produtoras e difusoras de tecnologias alternativas, identificadas por seu trabalho em prol do desenvolvimento rural sustentável, destaca-se aqui o Serviço de Tecnologias Alternativas (SERTA), selecionado para observação por cinco motivos:

1) Atua junto a grupos marginalizados na história econômica brasileira (os agricultores familiares) em espaços de difícil desenvolvimento desse modelo produtivo (o contexto de cana na Zona da Mata de Pernambuco e o semiárido no sertão e agreste do Estado);

2) Enfatiza a profissionalização e o protagonismo juvenil ${ }^{2}$, contribuindo para a geração de trabalho e renda que possibilitam a fixação de mão de obra, tradicionalmente exportada pela falta de oportunidades no campo;

3) Apresenta relevante influência nas determinações governamentais para a educação rural, tendo princípios de sua Proposta Educacional de Apoio ao Desenvolvimento Sustentável (PEADS) inseridos nas Diretrizes Operacionais para Educação do Campo (MEC, Parecer CNE/CEB n. ${ }^{\circ} 36 / 2001$ ), elaboradas pelo Conselho Nacional de Educação e homologadas pelo Ministério da Educação (MEC);

4) Em 2001, tornou-se uma Organização da Sociedade Civil de Interesse Público (OSCIP), o que possibilita a interação e a captação de recursos das esferas pública e privada;

5) Desde 2005, realiza cooperação internacional através da Rede Latino-Americana e do Caribe de Segurança Alimentar e Desenvolvimento Sustentável (RedLayc). ${ }^{3}$

Fundado em 1989, no agreste pernambucano, e transferido em 1996 para o município de Glória do Goitá-PE (microrregião de Vitória de Santo Antão), o SERTA dedica-se à geração de competências e à construção de aparato tecnológico para o desenvolvimento de comunidades rurais de forma sustentável.

Para tanto, atua junto a jovens (filhos e filhas de agricultores/as), educadores e produtores familiares, por meio do Curso de Formação de Agentes de Desenvolvimento Local (ADL) que, desde 2008, foi reconhecido pela Secretaria de Ciência, Tecnologia e Meio Ambiente (SECTMA), junto com o Conselho Estadual de Educação, como Curso Técnico em Agroecologia, voltado à Agricultura Familiar.

Dessa forma, a organização apresenta como finalidade o "desenvolvimento territorial" que, de acordo com o MDA (TORRENS, 2007), consiste em uma categoria analítica em construção que engloba a integração de políticas públicas, ampliação da participação social, universalização de programas básicos de cidadania e inclusão produtiva das populações pobres dos territórios. Esta última se manifesta pela assistência técnica e pesquisa, formação continuada e qualificação profissional, acesso ao crédito rural e segu-

\footnotetext{
${ }^{2}$ Segundo Costa e Vieira (2005), o protagonismo juvenil consiste em estimular os jovens em ações que dizem respeito aos problemas e à vida em comunidade, tornando-os corresponsáveis pelo desenvolvimento local e nacional. Concebe-os como fonte de iniciativas capazes de, aliando tradição e modernidade, aprimorar sistemas sociais pouco dinâmicos, quebrando ciclos de replicação das condições de marginalidade produtiva.

${ }^{3}$ Compreende (57) instituições em doze países e atua na transferência de conhecimento e intercâmbio de experiências entre os centros participantes, construindo-se um espaço de análise e reflexão. Visa, igualmente, estimular a formação de jovens profissionais, ligados às necessidades da comunidade e ativos na promoção do desenvolvimento das potencialidades locais, sob a égide da racionalidade ambiental e do compromisso social, dedicando-se a organizações voltadas para a segurança alimentar e para o fortalecimento da agricultura familiar.
} 
ros, apoio para o fortalecimento da agricultura familiar, especialmente dos agricultores em situação de fragilidade, caso de grande parte dos agricultores familiares (AF's) no semiárido.

A nosso ver, a perspectiva do desenvolvimento territorial aparece como uma conquista através da geração de trabalho e renda de forma social e ambientalmente sustentável e como meio de impulsionar a agricultura familiar. Vislumbra-se desenvolver o território através da difusão e da valorização de conhecimentos que possibilitem o melhor aproveitamento da propriedade e a ampliação da renda por meio do uso de tecnologias alternativas, da valorização da agricultura familiar como modelo social, ambiental e economicamente viável e de um conceito particular de educação, voltada às necessidades do trabalhador rural.

Por compreender o imperativo de transformar a educação rural como determinante para impulsionar mudanças profundas no campo, o SERTA dedicou seus primeiros anos à construção de uma proposta pedagógica voltada para articular conhecimento científico e saber tradicional, a PEADS (Proposta Educacional de Apoio do Desenvolvimento Sustentável).

De acordo Moura (2003), a PEADS resulta de progressivas reflexões e do contato com a educação formal e não formal. Tais práticas envolveram programas assistenciais, produtores, educadores e jovens em interações com diversas organizações da sociedade civil, sintetizando experiências complementares à escola e as vivências da educação popular no ensino formal.

Segundo o autor, essa proposta surge como uma crítica às condições marginais da educação no campo. Essa situação de inferioridade se deve, mais que à carência de investimentos na educação rural, aos valores de estímulo ao êxodo e de depreciação do trabalho e do trabalhador campesino e à negligência das características e necessidades da população rural.

O SERTA traz, portanto, como marco conceitual a sustentabilidade centrada no planejamento participativo com foco no jovem protagonista ${ }^{4}$ e em iniciativas de empoderamento social e tecnológico para a superação das limitações à produção agrícola familiar. Essa iniciativa perpassa pela compreensão da tecnologia como fator de desenvolvimento local integrado. Isso, aliado à formação de uma consciência crítica na juventude, visa impulsionar uma dinâmica de transformação das condições sociais, culturais e econômicas em espaços marcados pela resistência cultural e a grave deficiência educacional, uma vez que essas características limitam a realização de mudanças sociais significativas, replicando o ciclo de pobreza alimentado por séculos de exploração, insuficiência e ineficiência dos programas governamentais de assistência social.

\subsection{Resultados observados a partir da atuação do SERTA no semiárido pernambucano}

O SERTA, com 22 anos de trabalho, construiu dois centros tecnológicos chamados de UPPOs (Unidade Pedagógica Permacultural Orgânica), localizados nos municípios de Glória do Goitá-PE e Ibimirim-PE (Figura 1), onde são desenvolvidas, adaptadas e testadas novas tecnologias e é ministrado o Curso Técnico em Agroecologia, mais popularmente conhecido como Curso de Formação de Atores de Desenvolvimento Local (ADL).

Nesse período de atuação, de acordo com dados obtidos por meio de entrevistas na organização, o SERTA formou 10.000 técnicos - jovens, agricultores(as) e educadores(as) - em 48 municípios do Estado de Pernambuco, nas microrregiões da Mata Sul, Mata Norte, Agreste Meridional, Sertão do Moxotó e Sertão do Pajeú e recebe jovens da Mesorregião do Sertão do São Francisco (Figura 1). Destes, 750 foram formados no SERTA-Ibimirim, desde 2004, para atuar no semiárido pernambucano.

Através de sua proposta educacional (PEADS - Proposta Educacional de Apoio ao Desenvolvimento Sustentável), o Serviço de Tecnologias Alternativas atingiu primeiro a escola rural e depois as escolas urbanas, reorientando a metodologia docente quanto aos objetivos e valores implícitos nos conteúdos trabalhados em 70 escolas de 15 municípios.

Aliando ensino, pesquisa e extensão rural na produção e adaptação de tecnologias, o SERTA implantou, em cada UPPO, noventa soluções tecnológicas alternativas, aplicadas ao manejo de solo, água, animais e plantas, desenvol-

\footnotetext{
${ }^{4}$ De acordo com o SERTA (2011), nessa trajetória foi determinante, a partir de 1999, a participação da organização no programa "Aliança com o Adolescente para o Desenvolvimento Sustentável no Nordeste", idealizado por Viviane Senna (Instituto Ayrton Sena) e realizado em colaboração com a Fundação F. Kellogg, a Fundação Odebrecht e o Banco Nacional de Desenvolvimento Econômico e Social (BNDES).
} 


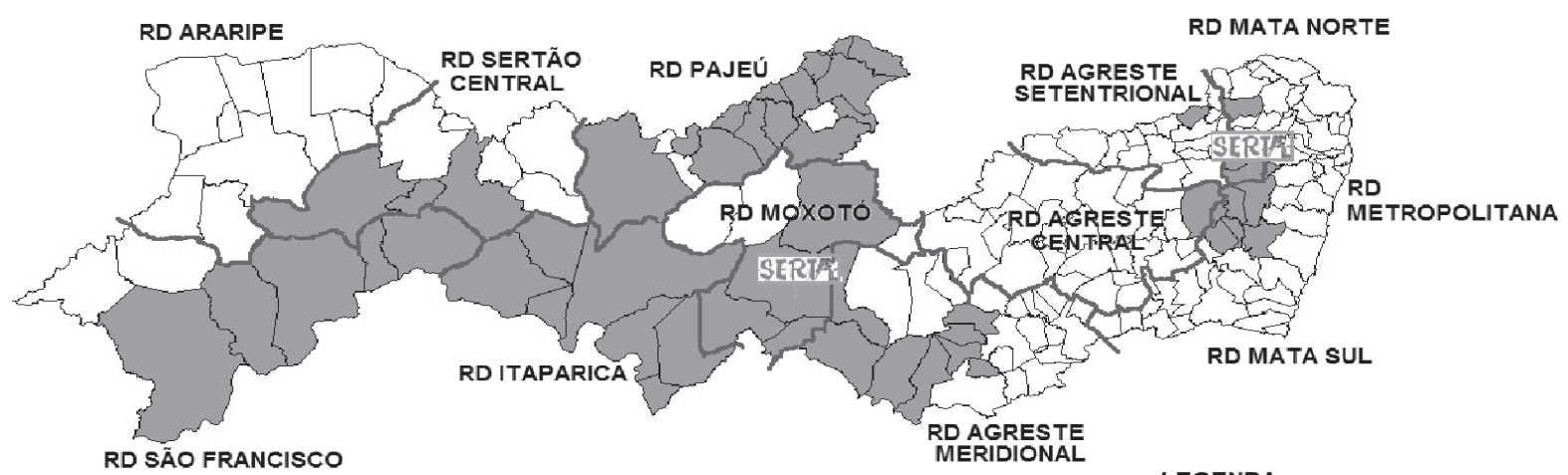

\section{LEGENDA}

SERTHân UPPO Unidade Pedagógica Permacultural Orgänica

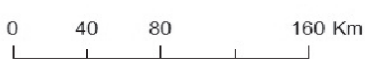

$\stackrel{N}{\Lambda}$

Área de Atuação do Serta

Divisão das RD's (Regiões de Desenvolvimento)

FIGURA 1 - Território de atuação do Serviço de Tecnologia Alternativa-SERTA, 2010

FONTE: COSTA, 2011
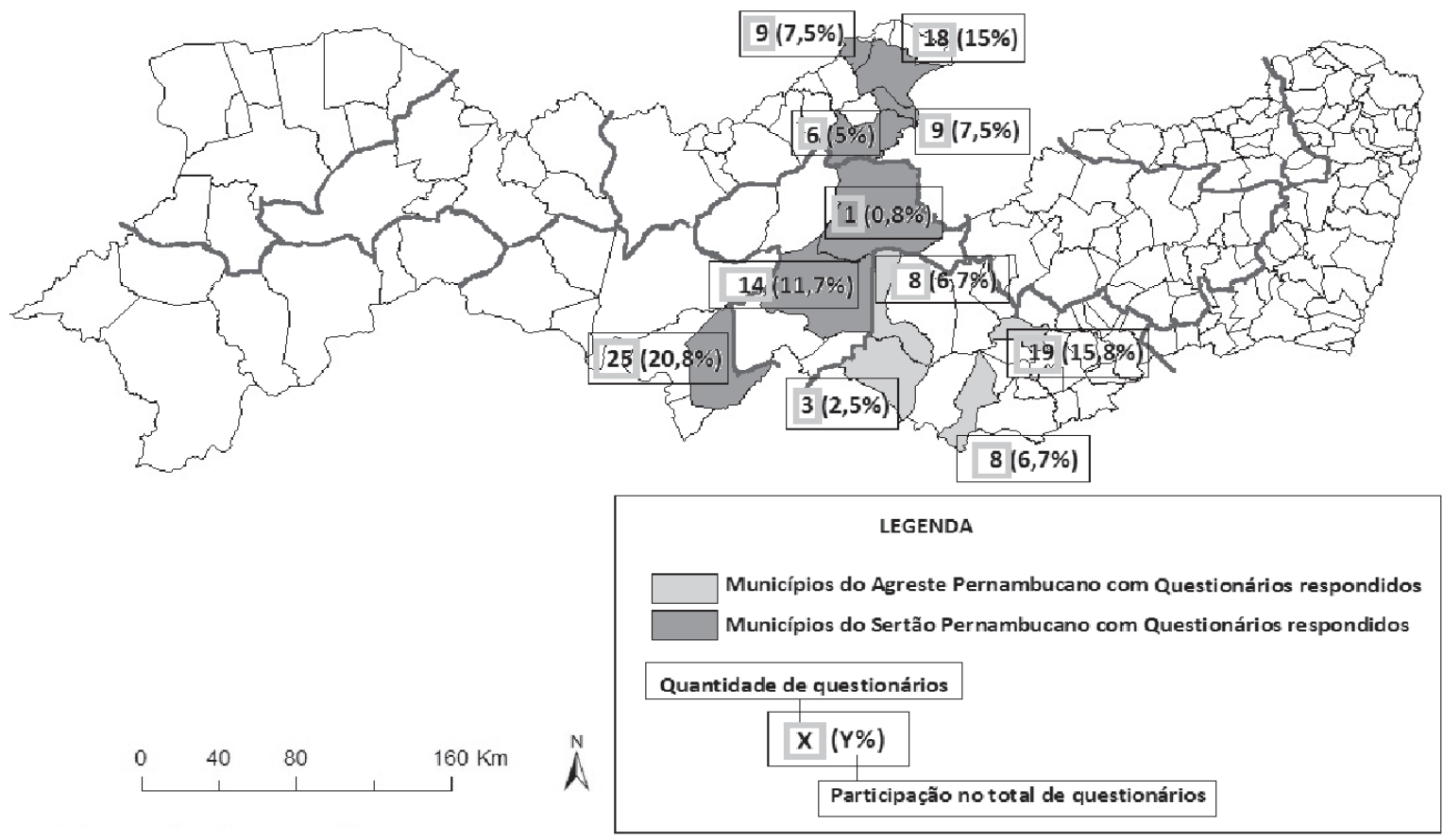

FIGURA 2 - Municípios pernambucanos sob atuação do SERTA com participação nos questionários respondidos, 2011

FONTE: COSTA, 2011 
vidas com o objetivo de melhor aproveitar os recursos da propriedade, solucionar problemas produtivos e fornecer uma alternativa de geração de renda para os agricultores (Quadro 2).

A fim de identificar a compreensão dos agricultores formados pelo SERTA a respeito dos resultados observados através do trabalho desenvolvido pela organização, no contexto específico do semiárido pernambucano, onde as fragilidades históricas da agricultura familiar brasileira somam-se a condições ecológicas rigorosas, aplicou-se 120 questionários com agricultores familiares, filhos de agricultores e educadores que fizeram ou estão fazendo o Curso Técnico em Agroecologia.

Os questionários foram aplicados nos dias 21 e 22 de julho de 2011, por ocasião da realização da diplomação de todas as turmas formadas pelo SERTA-Ibimirim, com integrantes das quatro turmas formadas nessa filial, sediada no povoado de Poço da Cruz, na área rural do município. Nesse momento, foram coletados dados de atores de 11 municípios do sertão e agreste pernambucanos distribuídos de acordo com a Figura 2.

Dos 120 pesquisados, $38(31,7 \%)$ pertencem ao agreste pernambucano, no qual a maior participação foi obtida entre os ADLs do município de Caetés, com 15,8\% dos questionários respondidos. Os demais 68,3\% (82 questionários) são de ADLs do sertão do Estado, no qual a maior participação encontra-se entre os municípios de Tacaratu (com 20,8\% dos questionários respondidos), São José do Egito (15\%) e Ibimirim (11,7\% dos questionários).

O questionário aplicado apresentou perguntas que visam identificar a visão anterior e posterior à formação obtida no SERTA, a fim de avaliar os impactos das tecnologias alternativas e da própria instituição com sua Proposta Educacional de Apoio ao Desenvolvimento Sustentável (PEADS), de autoria de Moura (2003). O questionário foi, portanto, dividido em três partes:

1 -Dados sobre o ADL e sua unidade produtiva (idade; escolaridade; categoria: agricultor, filho de agricultor, educador; localização e extensão da unidade produtiva; forma de acesso à terra ou forma de uso: arrendamento, parceria);

2 -Informações sobre a produção e seu destino antes da formação no SERTA (principais produtos cultivados; destinação da produção: comércio, consumo familiar; local de comercialização dos produtos e nível de dificuldades encontradas para produzir: inadequação do tamanho da propriedade às necessidades da família, acesso à água, acesso ao crédito, uso de técnicas inadequadas, (in) existência de mercado para os produtos e acesso a apoio técnico);

3 - Avaliação das condições de produção e vida do ADL depois do Curso Técnico em Agroecologia, onde se buscou verificar se os conhecimentos/ tecnologias aprendidos no SERTA-Ibimirim: possibilitaram diversificar a produção e ampliar as quantidades produzidas; alteraram a destinação dos produtos, atribuindo valor ao conteúdo aprendido de acordo com seus reflexos em cada categoria elencada.

Por meio destes questionários, teve-se acesso a alguns dados e declarações que destacam pontos importantes para a compreensão dos resultados da atuação da organização.

Os agricultores entrevistados, pais e mães de alunos do SERTA, declararam se beneficiar dos conhecimentos adquiridos por seus filhos. Entretanto, ao serem questionados sobre a satisfação quanto à carreira que o filho escolheu seguir, informaram a preferência por outras profissões, entre as quais é marcante o ingresso na carreira militar em $30 \%$ questionários, como forma de tirá-los da "vida na roça".

Ficam implícitos, nesse contexto, os conflitos entre as gerações, conforme ilustra a declaração do Informante A, uma vez que a formação ADL altera a dinâmica de transmissão do patrimônio imaterial, a cultura produtiva, marcante na definição de agricultor familiar no Brasil, onde o patrimônio material, terra, é substancialmente escasso dentro desse modelo produtivo, confirmando a perspectiva de Wanderley (1998).

Quando eu era menino, era assim: meu pai me levava pro roçado e ensinava o que eu tinha que fazer. Eu comecei na roça aos 7 anos. Nunca tive tempo pra estudar! Mas agora o tempo tá mudado. Os meninos têm escola e a escola é boa. Só que eu não aceitei muito bem no começo. É que eu achava estranho que meu filho aprendesse na escola como plantar. Achava que escola era pra aprender a ler, escrever e contar. Plantar quem ensinava era eu! Briguei "um bocado", sabe? Mas aí comecei a ver que meu filho tinha umas ideias boas e que dava resultado. Fui deixando ele mudar umas coisinhas e ficou bom. Mas no começo tinha briga mesmo. Sabe como é, esses meninos não sabem nada da vida, mas chegam querendo dar aula pros velhos. (Informante A, masculino, 53 anos, Agricultor, Pai de ADL formado na turma de 2008) 


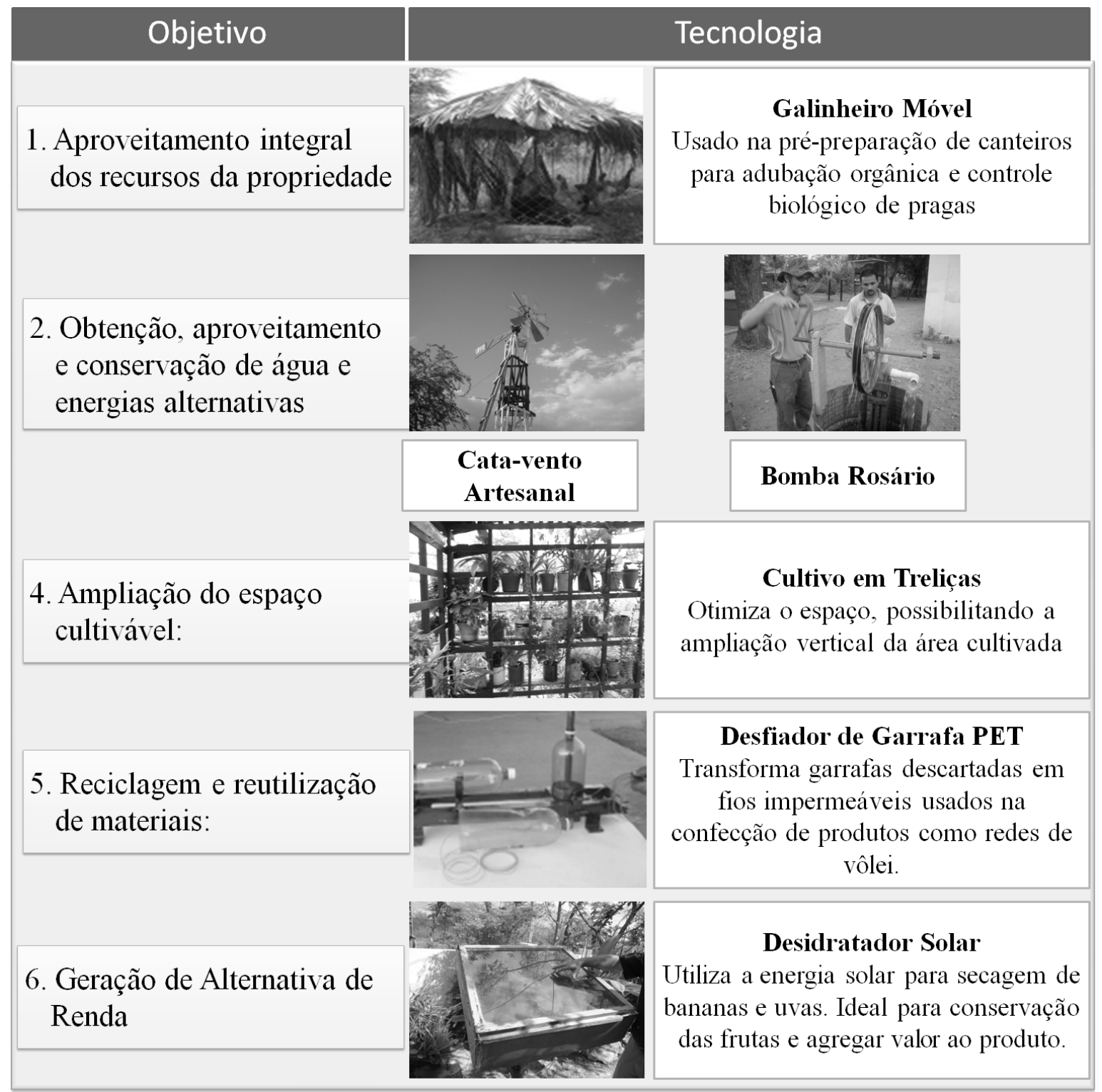

QUADRO 2 - Exemplos de objetivos e tecnologias alternativas produzidas pelo SERTA, 2010. FONTE: COSTA, 2011. 
Entre os filhos de agricultores em formação, para os quais a média de idade gira em torno dos 20 anos, a escolaridade dos informantes, por exigência do SERTA, é o nível médio (ou Normal Médio). A avaliação da formação de ADL a coloca como caminho viável para melhoria das técnicas de produção e do suprimento das necessidades da comunidade, gerando trabalho e renda.

Entre os atores, filhos e filhas de agricultores já formados, observou-se uma melhoria do quadro de escolaridade. Após o SERTA, 22\% declararam ter as condições necessárias para ingressar no nível superior, destacando interesse nos cursos de Biologia, Agronomia e Ciências Sociais como forma de ampliar seus conhecimentos e sua capacidade de ação social ambientalmente responsável. No entanto, apenas $5 \%$ ingressaram, de fato, em curso superior. Isso confirma a expectativa dos atores em formação, mas, diante das necessidades da região, mostra-se insuficiente.

Quanto à posse da terra, $100 \%$ dos informantes afirmaram que a propriedade onde trabalham pertence à família, sendo $20 \%$ terra de herdeiros, pertencente aos avós ainda vivos. A extensão média das propriedades dos entrevistados é de 13 ha, contudo, mesmo entre esses a posse da terra é dissimétrica. $78 \%$ dos pesquisados dispõem de unidades produtivas com dimensões inferiores ou iguais a essa média, enquanto os demais $22 \%$ apresentaram unidades com extensão entre 27 e 50 ha.

Entre os principais cultivos realizados antes da participação no SERTA-Ibimirim (Quadro 3), como é esperado pela prevalência da agricultura de sequeiro, que exige o cultivo de espécies de ciclo vegetativo curto, aparecem milho e feijão em $100 \%$ dos questionários respondidos, mandioca ou outras raízes apareceram em $40 \%$ e o cultivo de frutas (incluindo tomate) em 30\%.

Antes do SERTA, 70\% dos cultivos eram destinados apenas ao consumo familiar. Os outros $30 \%$ comercializavam seus produtos nas feiras de seus municípios, a preços bastante reduzidos, apresentando os intermediários como um grande problema para a obtenção de preços mais elevados.

Após o SERTA, foram acrescidas a esses tradicionais produtos as hortaliças em $29 \%$ e a criação de caprinos, ovinos e bovinos em $10 \%$ dos informantes, além da inserção de outras espécies de grãos, destinados à alimentação humana e animal, em $21 \%$. O percentual dos que comercializam subiu para $50 \%$, agora não apenas nas feiras locais, mas na periferia de seu município, ampliando o mercado e obtendo preços melhores para a venda dos produtos.

Quando questionados a respeito das dificuldades encontradas para produzir, os pesquisados revelaram o padrão observado no Gráfico 1.

Quanto à disponibilidade de água, 50\% dos agricultores e filhos de agricultores formados ou em formação pelo SERTA responderam que o acesso à água, ainda que através de carros de boi ou de cisternas ou até por meio de cursos fluviais temporários, é suficiente para atender às necessidades da produção. Apresentam, todavia, como grande problema a gestão da água para seu uso racional e conservação.

QUADRO 3 - PRINCIPAIS CULTIVOS REALIZADOS ANTES E DEPOIS DA FORMAÇÃO NO SERTA-IBIMIRIM, 2011

\begin{tabular}{|c|c|c|c|}
\hline \multirow{2}{*}{ PRODUTO } & \multicolumn{2}{|c|}{ QUESTIONÁRIOS } & \multirow{2}{*}{ PARTICIPAÇÃO (\%) } \\
\hline & Antes & Depois & \\
\hline Feijão & 120 & 120 & 100 \\
\hline Mandioca e outras raízes & 48 & 48 & 40 \\
\hline Hortaliças & --- & 35 & 29 \\
\hline Caprinos, ovinos e bovinos & --- & 12 & 10 \\
\hline Outras espécies de grãos. & --- & 25 & 21 \\
\hline
\end{tabular}

FONTE: COSTA, 2011. 


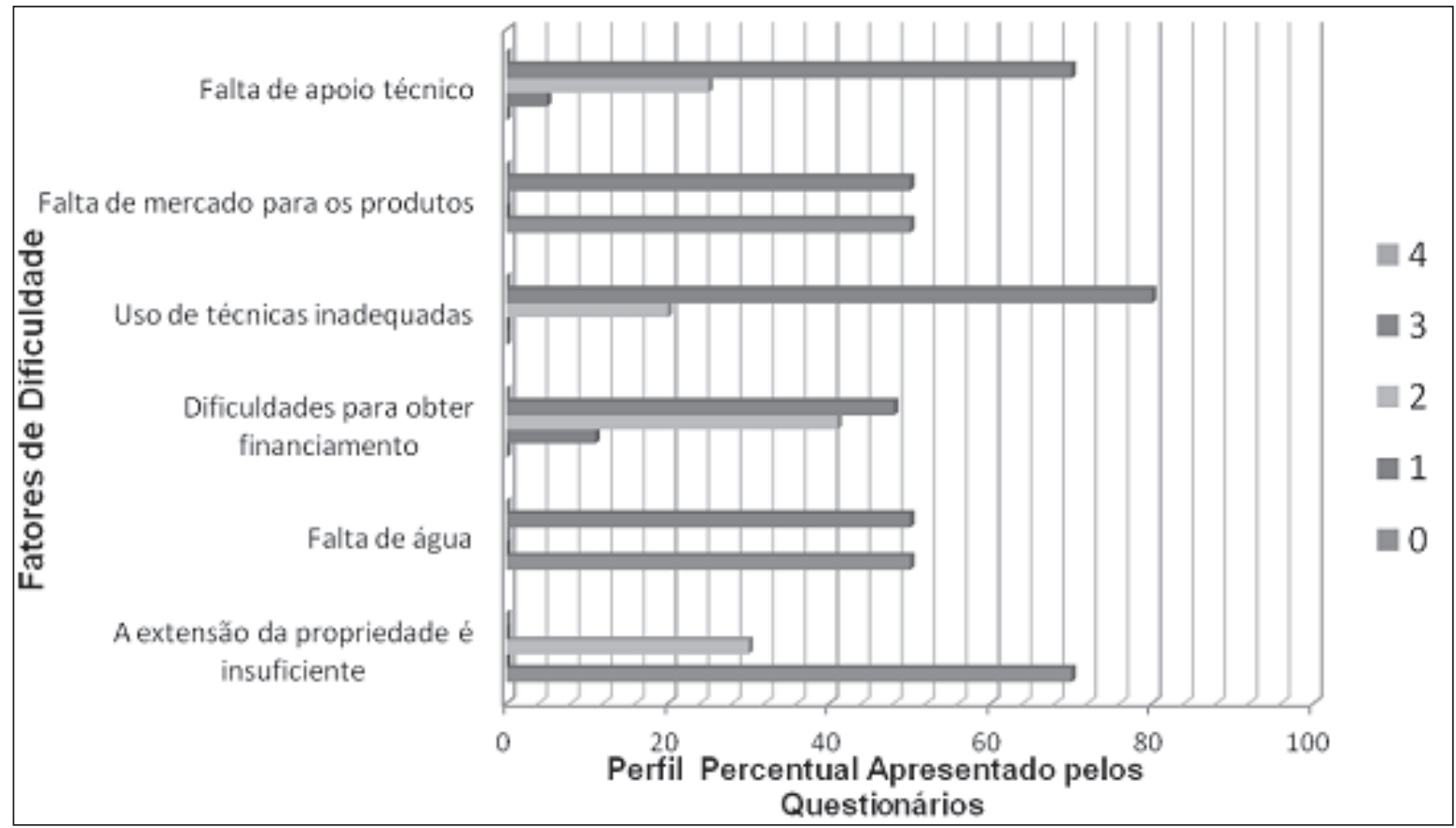

GRÁFICO 1 - Fatores que dificultavam a realização da produção antes da formação do Serta-Ibimirim e sua classificação por nível de dificuldade, 2011

FONTE: Costa, 2011

*Nível de dificuldade (0) nenhum; (1) baixo; (2) razoável; (3) elevado; (4) torna impossível produzir.

Os outros $50 \%$ dos pesquisados declararam que as condições de acesso à água dificultam muito a produção, tornando quase impossível o cultivo fora do período de chuvas. É importante destacar que os atores que declararam ter maior dificuldade de produzir pela falta de acesso à água localizam-se, principalmente, no Sertão do Pajeú, onde as médias de pluviosidade giram em torno dos $400 \mathrm{~mm}$ anuais.

No que se refere ao tamanho da propriedade, embora esta se apresente reduzida, foi descrita como suficiente por $70 \%$ dos informantes e como elemento que dificulta razoavelmente pelos $30 \%$ restantes. Merece destaque a produção para consumo, já que $50 \%$ praticam agricultura de subsistência, enquanto que os outros $50 \%$ encontram na falta de mercado um grande empecilho para a ampliação da renda familiar, em virtude dos baixos valores recebidos pelos produtos comercializados.

De acordo com os dados obtidos, os fatores que, na opinião dos ADLs formados ou em formação, mais dificultam (dificultaram) a produção são o uso de técnicas inadequadas de cultivo, aparecendo com nível (3) em $80 \%$ dos questionários respondidos, e a falta de apoio técnico, com nível (3) para 70\% dos informantes. Para esses atores, o uso exclusivo de ferramentas de trabalho, como a enxada, e a mão de obra familiar não favorecem um cultivo adequado. Sobre isso declarou um dos pesquisados:

Tirar da terra o sustento é muito difícil no Sertão. Se não se sabe o modo mais inteligente, a gente fere a terra. Tenta tirar algo dela, mas acaba só destruindo o pouco que tem. Meu pai usa só enxada e reza prá chover. Eu vim aqui prá ver como fazer a enxada render mais. Se ele deixar, depois que eu aprender eu mostro como fazer, para ver se assim ele trabalha menos e ganha mais (Informante B, Masculino, 23 anos, filho de Agricultor, ADL em formação).

De todos os informantes, apenas $5 \%$ já fizeram uso de financiamento e destacaram a dificuldade para a obtenção desse recurso, apesar dos programas de apoio à agricultura 
familiar, como o PRONAF (Programa Nacional de Fortalecimento da Agricultura Familiar). Dadas as dificuldades apontadas, $48 \%$ alegam a falta de financiamento como fator dificultador da produção em nível (3).

É importante considerar que nenhum dos fatores, destacados pelo Gráfico 1, foi apresentado pelos informantes como capaz de tornar impossível a produção, mesmo em situação de reduzida área por unidade produtiva, água pouco abundante, falta de acesso a crédito e aparato técnico tradicional.

O Gráfico 2 apresenta os valores atribuídos para as contribuições da formação Técnica em Agroecologia e os resultados obtidos em cada categoria. Em 100\% dos questionários verificou-se que a utilização da propriedade, a transmissão tecnológica e o apoio técnico são as principais contribuições do Serviço de Tecnologias Alternativas, aparecendo com nível (4) em cerca de 90\% dos questionários respondidos.

Bem menos frequente aparece a conquista de novos mercados, apontada em $20 \%$ dos questionários como nível (3), sendo atribuída principalmente ao aumento da quantidade e da qualidade dos produtos obtidos através do uso ambientalmente racional dos recursos e do emprego de tecnologias alternativas. Sobre isso, uma informante respondeu:
Antes eu tinha coqueiro, plantava goiaba, banana e acerola, mas não dava fruta. Eu queimava as folhas pra limpar o terreno, plantava, mas não colhia quase nada. Depois que eu comecei a reutilizar a água do banho para as plantas e a usar o adubo orgânico que eles ensinaram meu filho a fazer, a usar as folhas em vez de queimar tudo, precisa ver como tá bonito. Tudo carregado de fruta. Agora tem banana todo dia lá em casa. É tanta banana que eu tenho que dar para os vizinhos, se não apodrece. (Informante C, Feminino, 47 anos, Agricultora, Mãe de ADL formado em 2006).

Não se constatou impacto dos conhecimentos aprendidos com o SERTA-Ibimirim na concessão de financiamentos, o que se atribui, majoritariamente, às dificuldades de se aprovar crédito para a agricultura familiar em clima semiárido, resultado da concepção errônea de improdutividade e impossibilidade de retorno do investimento. Essa realidade prevalece, apesar das políticas governamentais de incentivo à produção familiar proporcionadas pelo PRONAF na última década.

As tecnologias que mais foram citadas dizem respeito à gestão adequada da água, que é considerada como um recurso escasso no Sertão, logo, necessitando de preventiva aplicação racional de técnicas apropriadas de armazenamen-

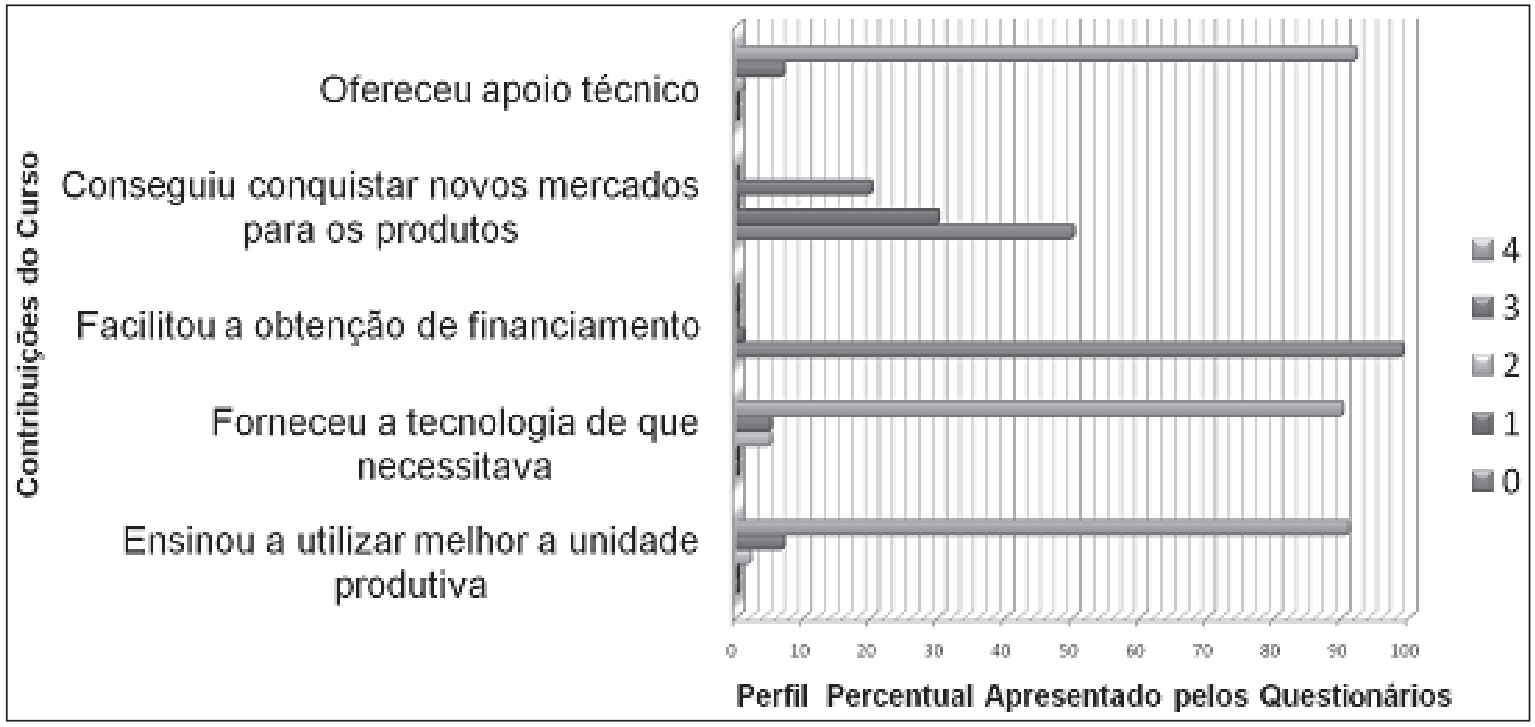

GRÁFICO 2 - Contribuições do curso de formação do SERTA-Ibimirim na unidade produtiva e resultados obtidos, 2011 FONTE: Costa, 2011.

* (0) não ajudou; (1) ajudou pouco; (2) ajudou razoavelmente; (3) ajudou muito; (4) mudou meu modo de produzir. 
to e conservação. Outro grupo importante de tecnologias citadas diz respeito à adubação e à conservação dos solos. Em menor escala, aparecem as tecnologias voltadas à agregação de valor ao produto agropecuário, indicando a não utilização do potencial para a consolidação da agroindústria familiar no sertão.

Quando questionados sobre a maior dificuldade para a aplicação das tecnologias alternativas aprendidas com o SERTA, dois fatores chamam a atenção: primeiro, o custo das tecnologias. Mesmo tendo uma forte base na reutilização de materiais e na construção de soluções de baixo custo, nem todas as tecnologias foram completamente acessíveis aos agricultores, que se limitaram ao uso de soluções mais baratas, para o que seria fundamental a obtenção de financiamento. Segundo, a tradição produtiva da família, que opõe resistência à inserção de novas tecnologias e a uma nova visão a respeito da unidade de produção, impedindo, por vezes, que se apliquem os conhecimentos adquiridos.

Quando se questiona "O que o SERTA mais mudou na vida dos pesquisados?", a resposta não girou somente em torno da produção, do suprimento de alimentos ou da renda. $\mathrm{O}$ que se destaca é a possibilidade de permanecer na terra. $\mathrm{O}$ SERTA, segundo os ADLs informantes, garantiu os meios para gerar trabalho e renda em seu local de origem, produzindo transformação na dinâmica familiar e na comunidade e ainda mais: apontando para as possibilidades e limitações de programas de desenvolvimento territorial nesta região.

\section{Considerações finais}

$\mathrm{O}$ estudo de caso nos indica que o incentivo à produção de tecnologias alternativas, fundamentado na racionalidade ambiental, permitiu a transformação das práticas culturais e produtivas, tais como: alteração no uso da terra e dos recursos hídricos, identificação de novas espécies cultiváveis, utilização dos resíduos orgânicos para fertilização das lavouras, melhor aproveitamento dos recursos da propriedade, bem como possibilitou a fixação da mão de obra no campo, de maneira produtiva. Da mesma forma, os resultados da aplicação destas tecnologias, em um território sob o clima semiárido, as colocam como elemento importante na superação de um contexto de exclusão tecnológica, econômica e social que marca a agricultura familiar no Brasil e, especialmente, no Nordeste, onde as iniciativas governamentais, embora importantes e necessárias, são escassas e insuficientes.
A observação do campo nos confirma o papel integrador e a viabilidade econômica da agricultura familiar, bem como desmistifica o conceito de improdutividade do ambiente semiárido, já que, se alterando a gestão da propriedade, ao se considerar as complexas relações que envolvem os processos naturais, e utilizando-se as soluções tecnológicas que se inserem nessa lógica, todos os informantes da pesquisa, embora não tenham conseguido oferecer dados quantitativos que nos permitissem mensurar as porcentagens de crescimento, identificaram o aumento da quantidade e da qualidade de seus produtos.

Contudo, embora seja destacada a importância da atuação de organizações como o SERTA, principalmente em um contexto carente de iniciativas pautadas em um conceito ambientalmente racional desenvolvimento, os resultados são minimizados pelas condições socioeconômicas da população, tornando inacessíveis mesmo certas tecnologias alternativas que, por definição, são caracterizadas pelo baixo custo.

Isso reflete as consequências de um processo histórico de escolhas e direcionamentos políticos de incentivo à grande produção monocultora e latifundiária como caminho para o "desenvolvimento" econômico e social pautado no modelo agroexportador, industrial e urbano. Dessa forma, ignorou-se a experiência de governos que já haviam alcançado o sonhado "desenvolvimento", os quais identificavam na agricultura familiar um elemento importante para realizar essa transição de forma socialmente menos danosa.

Tal antecedente que marca o setor agropecuário brasileiro, historicamente caracterizado pela concentração da propriedade da terra, construiu para a agricultura familiar uma visão de modelo residual fadado ao desaparecimento. De igual forma, alienou-se desses agricultores camponeses a característica de transmissão do patrimônio material, fazendo das características da mão de obra e das técnicas de produção os principais elementos de identidade do(s) grupo(s) que se encontra(m) em situação marginal no panorama econômico brasileiro, apesar da identificação de seu crescimento, claramente impulsionado pelas políticas de incentivo, e de sua capacidade produtiva, conforme atestado no último Censo Agropecuário (IBGE, 2006).

De acordo com dados do referido Censo, em 2006, $38 \%$ do valor bruto da produção agrícola veio da agricultura familiar, ainda que esta ocupasse apenas $24,3 \%$ da área total dos estabelecimentos rurais e representasse $84,4 \%$ do número destes, com área média de 18,37 hectares cada. Em contraposição, a agricultura não familiar, que ocupa $75,7 \%$ 
da área total e corresponde a apenas $15,6 \%$ dos estabelecimentos, os quais possuem extensão média de 309,18 ha, produziu o equivalente a $62 \%$ do valor bruto da produção agrícola. De acordo com o mesmo Censo, o Nordeste do país responde por $50 \%$ do número e $35 \%$ da área total dos estabelecimentos rurais familiares, sendo que $82,7 \%$ da população da região ocupada em atividades agropecuárias estão na produção familiar.

Esses dados confirmam que a concentração dos meios de produção configurada pela grande propriedade não pode ser, sem exagero, indício de superior eficiência produtiva, já que, enquanto os agricultores familiares produziam $\mathrm{R} \$$ 677,00/ha/ano, a produção não familiar alcançou apenas R\$ 358,00/ha/ano. Entretanto, demonstram também as dificuldades representadas pela concentração dos meios de produção, entre os quais se encontra o fator tecnológico, o que a atuação de organizações produtoras e difusoras de tecnologias alternativas, como o SERTA, tenta amenizar.

A atuação do SERTA-Ibimirim amortiza algumas necessidades urgentes e fundamentais: apoio técnico e acesso à tecnologia, auxiliando na remediação da dívida pública para com a agricultura familiar e o trabalhador rural. Mas existem outras necessidades elementares.

Primeiro, não se pode ampliar a produção, visando ao mercado, sem terra para cultivar. De acordo com o INCRA (1997), a delimitação das Zonas Típicas de Módulo Rural (ZTM) indica que, para a região considerada, as unidades de produção devem ter dimensão mínima de 30 hectares, quando ocupadas com lavouras temporárias, e 25 hectares, se ocupadas com lavouras permanentes, valores bem acima da média encontrada entre os pesquisados (13 ha), comprometendo sua capacidade de produzir, até mesmo para o suprimento das necessidades familiares.

\section{Referências}

ABIKO, A. K. et al. Tecnologias apropriadas em construção civil. In: Tecnologia e materiais alternativos de construção. Campinas: Editora da UNICAMP, 2003. Disponível em: $<$ http://alexabiko.pcc.usp.br/artigos/TecnologiasApropriadas. pdf>. Acesso em: julho de 2009.

ALTVATER, Elmar. [1938] O preço da riqueza: pilhagem ambiental e a nova (des)ordem mundial. São Paulo: Ed. UNESP, 1995.
Segundo, torna-se muito difícil melhorar a produção sem crédito. Conforme mostra o panorama encontrado por meio dos questionários aplicados, a atuação do SERTA não proporcionou ampliação significativa na obtenção de financiamentos, um indício da permanência de uma visão distorcida que identifica o semiárido como improdutivo e a agricultura familiar como incapaz de gerar, de forma lucrativa, alimentos e, principalmente, matéria-prima para as indústrias.

E finalmente, entre os agricultores pesquisados, a ampliação do mercado para os produtos dos ADLs mostrou-se presente, mas pouco dinâmica remanescente de uma cultura produtiva regional difícil de modificar e fator de replicação das condições marginais dos AFs. Deve-se reconhecer o valor social e econômico da produção para subsistência, que supre parte significativa das necessidades da família. Contudo, a dependência extrema da produção agrícola para suprimento destas necessidades básicas é arriscada, sobretudo em um contexto ambiental (ecológico, mas, principalmente, social e tecnológico) vulnerável.

A transformação das condições de vida e renda dos agricultores familiares depende em grande parte do reconhecimento das potencialidades de seu ambiente, adequando-se a produção a suas características e identificando-se oportunidades econômicas, bem como de sua inserção no mercado, como já defendia Celso Furtado no Grupo de Trabalho para o Desenvolvimento do Nordeste (GTDN, 1959).

Não se trata, portanto, de ignorar os fatores econômicos, mas de condicioná-los à existência de viabilidade social e ecológica, fundamental para a reprodução das práticas produtivas, logo, de interesse vital para a manutenção dos elementos que mantêm saudável a economia de um território e garantem a sobrevivência de comunidades.

CALLAN, Scott; THOMAS, Janet M. Economia Ambiental: aplicações, políticas e teoria. 3. ed. Mason (Ohio): Thompson/ South-Western, 2009.

CASTOR, B. V. J. Tecnologia apropriada: uma proposta de critérios de avaliação e sua aplicação. Revista de Administração, v. 18, n. 2, p. 40-47, abr./jun. 1983.

CODETEC - Unicamp. Considerações sobre tecnologia apropriada. Campinas: Unicamp, 1979. 
COSTA, Antonio Carlos; VIEIRA, Maria Adenil. Protagonismo juvenil: adolescência, educação e participação democrática. Recife: FTD/Fundação Odebrecht, 2005.

COSTA, Sunamita Iris Rodrigues Borges. Impactos da utilização de tecnologias alternativas no desenvolvimento ambientalmente racional da agricultura familiar no semiárido pernambucano. Dissertação (Mestrado) - Programa de Pós-Graduação em Desenvolvimento e Meio Ambiente da Universidade Federal de Pernambuco. Recife, 2011.

DICKSON, David. The politics of alternative technology. New York: Universe Books, 1975.

ELLUL, J. The technological society. New York: Vintage Books, 1954.

GTDN - Grupo de Trabalho para o Desenvolvimento do Nordeste. Uma política de desenvolvimento econômico para o Nordeste. Recife: SUDENE, 1959.

GUANZIROLI, C. et al. Agricultura familiar e reforma agrária no século XXI. FAO/MDA. Rio de Janeiro: Garamond, 2001.

HARVEY, David. Condição pós-moderna: uma pesquisa sobre as origens da mudança cultural. 11. ed. São Paulo: Loyola, 2002.

IBGE - Instituto Brasileiro de Geografia e Estatística. Relatório Preliminar para a Agricultura Familiar do Censo Agropecuário, 2006. Disponível em: <http://www.ibge.gov.br/home/ estatistica/economia/agropecuaria/censoagro/brasil_2006/ Brasil_censoagro2006.pdf $>$. Acesso em: julho de 2010.

INCRA - Instituto Nacional de Colonização e Reforma Agrária. Instrução Especial/INCRA n. 50, de 26 de agosto de 1997. Publicada no Diário Oficial da União. Seção I, n. 169, p. 19.240 a 19.243, de 03/09/97. Estabelece as Zonas Típicas de Módulo - ZTM e estende a Fração Mínima de Parcelamento - FMP, prevista para as capitais dos Estados para outros municípios. Disponível em: <http://pt.scribd.com/doc/55136081/IE50260897>. Acesso em: maio de 2010.

JÉQUIER, N. Appropriate Technology. Development Centre of the Organization for Economic Co-Operation and Development. Paris: OCDE, 1976.

LEFF, Enrique. Epistemologia ambiental. 3. ed. São Paulo: Cortez, 2002.

Saber ambiental: sustentabilidade, racionalidade, complexidade, poder. 6. ed. Petrópolis: Vozes, 2008.

LOVINS, Amory. Energy Strategy: The road not taken. Journal Foreign Affairs, n. 55, p. 94, out. 1976.
MORIN, Edgar. Ciência com consciência. 9. ed. rev. e modif. pelo autor. Rio de Janeiro: Bertrand Brasil, 2005.

MOTA, José Aroudo. Enfoques sistêmico e termodinâmico dos recursos naturais, 2010. Programa Nacional da Racionalização do Uso dos Derivados do Petróleo e Gás Natural, CONPET Ministério de Minas e Energia. Disponível em: $<$ http://www. conpet.gov.br/guia/guia_busca.php?id_guia_categoria $=0 \&$ s egmento $=$ corporativo\&string $=$ Enfoques + Sist $\%$ EAmico $+e+$ Termodin $\%$ E 2 mico + dos + Recursos + Naturais $>$. Acesso em: abril de 2010 .

MOURA, Abdalaziz de. Princípios e fundamentos da Proposta Educacional de Apoio ao Desenvolvimento Sustentável (PEA$D S)$ : uma proposta que revoluciona o papel da Escola diante das pessoas, da sociedade e do mundo. 2. ed. Glória de Goitá-PE: Serviço de Tecnologias Alternativas, 2003.

OLIVEIRA, Eva Aparecida. A técnica, a techné e a tecnologia. Revista Eletrônica Intinerarius Reflectionis, v. 2, n 5, jul./dez 2008. Disponível em: <http://www2.jatai.ufg.br/ojs/index. php/itinerarius/article/viewFile/510/205>. Acesso em: julho de 2009.

PSF - Portal São Francisco. Queimadas e desmatamentos. 2010. Disponível em: <http://www.portalsaofrancisco.com. br/alfa/meio-ambiente-desmatamento/queimadas-e-desmatamentos.php>. Acesso em: fevereiro de 2010.

SÁBATO, Ernesto R. [1951] Homens e engrenagens: reflexões sobre o dinheiro, a razão e a derrocada de nosso tempo. Campinas: Papirus, 1993.

SANTOS, Boaventura de Souza. Pela mão de Alice: o social e o político na pós-modernidade. 7. ed. Porto: Afrontamentos, 1999.

SCHUMACHER, Ernest F. Small is Beautiful: Economics as if people mattered. New York: Perennial Library, 1973.

. The Politics of Alternatives in Technology. Alternatives 1. New York: Universe Books, 1975.

SERTA. Serviço de Tecnologias Alternativas, 2011. Disponível em: <http://www.serta.org.br/>. Acesso em: abril de 2011.

TORRENS, João Carlos Sampaio. Território e desenvolvimento: a experiência de articulação territorial do Sudoeste do Paraná. Ministério do Desenvolvimento Agrário - MDA. Projeto de Cooperação Técnica FAO/MDA, 2007. Disponível em: $<$ http://www.deser.org.br/publicacoes/estudosTerritoriais_2. pdf $>$. Acesso em: junho de 2012.

UHLMANN Günter Wilhelm. Teoria Geral dos Sistemas: do atomismo ao sistemismo (uma abordagem sintética das prin- 
COSTA, S. I. R. B. da; SILVA, M. M. da. A racionalidade ambiental na construção de tecnologias alternativas...

cipais vertentes contemporâneas desta prototeoria). São Paulo: no prelo, 2002. Disponível em <http://www.institutosiegen. com.br>. Acesso em: janeiro de 2011.

VARGAS, Milton. Para uma filosofia da tecnologia. São Paulo: Alfa-Omega, 1994.
WANDERLEY, Maria de Nazareth Baudel. Apresentação da problemática. In: LAMARCHE, Hugues. Agricultura familiar: do mito à realidade. v. 2. São Paulo: Unicamp, 1998.

WINNER, Langdon. The Political Philosophy of Alternative Technology: historical roots and present prospects. Journal Technology in Society, v. 1. p. 77-89, 1979.

Recebido em dezembro de 2011. Aceito em junho de 2012. Publicado em junho de 2012. 